ISSN 2078-3744. Вісник Львів. ун-ту. Серіл мех.-мат. 2018. Випуск 86. С. 109-115

Visnyk of the Lviv Univ. Series Mech. Math. 2018. Issue 86. P. 109-115

http://publications.lnu.edu.ua/bulletins/index.php/mmf

doi: http://dx.doi.org/10.30970/vmm.2018.86.109-115

УДК $517.51,515.12$

\title{
THE INVARIANCE OF THE LINDELÖF NUMBER UNDER SOME DISCONTINUOUS FUNCTIONS
}

\author{
Dedicated to the 60th birthday of M. M. Zarichnyi
}

\section{Bogdan BOKALO, Nadiya KOLOS}

Ivan Franko National University of Lviv, Universitetska Str., 1, 79000, Lviv, Ukraine

e-mail:b.m.bokalo@gmail.com,nadiya_kolos@ukr.net

\begin{abstract}
A function $f: X \rightarrow Y$ between topological spaces is called scatteredly continuous (barely continuous) if for each non-empty (closed) subspace $A \subset X$ the restriction $\left.f\right|_{A}$ has a point of continuity. We show that if $f: X \rightarrow Y$ is a scatteredly continuous (barely continuous) surjective function between topological spaces, then for each natural number $n$ we have $\operatorname{hl}\left(Y^{n}\right) \leqslant \operatorname{hl}\left(X^{n}\right)$ $(l(Y) \leqslant h l(X)$, respectively).

Key words: scatteredly continuous function, weakly discontinuous function, barely continuous function, Lindelöf number.
\end{abstract}

\section{INTRODUCTION}

By definition, a function $f: X \rightarrow Y$ between topological spaces is scatteredly continuous if for each non-empty subspace $A \subset X$ the restriction $f \mid A$ has a point of continuity.

We recall that a function $f: X \rightarrow Y$ is called barely continuous if for each non-empty closed subspace $A \subset X$ the restriction $f \mid A$ has a point of continuity.

Following [19] we define a function $f: X \rightarrow Y$ to be weakly discontinuous if for each subspace $A \subset X$ the set $D\left(\left.f\right|_{A}\right)$ of discontinuity points of the restriction $\left.f\right|_{A}$ is nowhere dense in $A$.

Obviously, every weakly discontinuous function is scatteredly continuous and each scatteredly continuous function is barely continuous.

As an example of scatteredly continuous, not a weakly discontinuous function one can take an identity function $f: \mathbb{R} \rightarrow \mathbb{R}_{\mathbb{Q}}$ from the real line equipped with the standard topology $\tau$ to the real line endowed with the topology generated by the subbase $\tau \cup\{\mathbb{Q}\}$.

2010 Mathematics Subject Classification: $54 \mathrm{C} 08$

(c) Bokalo, B., Kolos, N., 2018 
In [2] it is proved, in particular, that any scatteredly continuous function $f: X \rightarrow Y$ into a regular space $Y$ is weakly discontinuous.

Recall that the Riemann function is a function $R:[0,1] \rightarrow[0,1]$ defined as follows

$$
R(x)= \begin{cases}\frac{1}{n}, & \text { if } x=\frac{m}{n} \text { is a rational number; } \\ 0, & \text { if } x \text { is irrational. }\end{cases}
$$

Obviously, the Riemann function is an example of a barely continuous, but not scatteredly continuous function.

These discontinuous functions arose naturally and were studied in various fields of mathematics under different names (see also [12, 4, 9, 10, 11, 5, 6, 8, 13, 15, 3, 17).

Some topological properties preserved by weakly discontinuous functions were detected in [7. In particular, it was shown that if $f: X \rightarrow Y$ is a weakly discontinuous surjective map between topological spaces, then

(1) $n w(Y) \leqslant n w(X)$

(2) $h l(Y) \leq h l(X)$

(3) $h d(Y) \leq \max \{h d(X), h l(X)\}$.

In this paper we analyze the behavior of the Lindelöf number under scatteredly continuous and barely continuous functions. We show that if $f: X \rightarrow Y$ is a scatteredly continuous (barely continuous) surjective function between topological spaces, then for each natural number $n$ we have $\operatorname{hl}\left(Y^{n}\right) \leqslant \operatorname{hl}\left(X^{n}\right)(l(Y) \leqslant h l(X)$, respectively).

1.1. Terminology and notations. Our terminology and notation are standard and follow [1] and [14]. A "space" always means a "topological space". Maps between topological spaces can be discontinuous.

For a subset $A$ of a topological space $X$ by $\operatorname{cl}_{X}(A)$ or $\bar{A}$ we denote the closure of $A$ in $X$ while $\operatorname{Int}(A)$ stands for the interior of $A$ in $X$. For a function $f: X \rightarrow Y$ between topological spaces by $C(f)$ and $D(f)=X \backslash C(f)$ we denote the sets of continuity and discontinuity points of $f$, respectively.

Suppose that we are given a family $\left\{X_{s}: s \in S\right\}$ of topological spaces. We consider the Cartesian product $X=\prod_{s \in S} X_{s}$ of the sets $\left\{X_{s}: s \in S\right\}$ with Tychonoff topology.

Suppose that we are given two families $\left\{X_{\alpha}\right\}_{\alpha \in S}$ and $\left\{Y_{\alpha}\right\}_{\alpha \in S}$ of topological spaces and a family of maps $\left\{f_{\alpha}\right\}_{\alpha \in S}$, where $f_{\alpha}: X_{\alpha} \rightarrow Y_{\alpha}$. The map assigning to the point $x=\left\{x_{\alpha}\right\}_{\alpha \in S} \in \prod_{\alpha \in S} X_{\alpha}$ the point $\left\{f_{\alpha}\left(x_{\alpha}\right)\right\}_{\alpha \in S} \in \prod_{\alpha \in S} Y_{\alpha}$ is called the Cartesian product of the maps $\left\{f_{\alpha}\right\}_{\alpha \in S}$ and is denoted by $\prod_{\alpha \in S} f_{\alpha}$ or $f_{1} \times f_{2} \times \cdots \times f_{k}$ if $S=\{1,2, \ldots, k\}$.

By $\mathbb{R}$ and $\mathbb{Q}$ we denote the spaces of real and rational numbers, respectively; $\omega$ stands for the space of finite ordinals (= non-negative integers) endowed with the discrete topology. We shall identify cardinals with the smallest ordinals of the given cardinality.

All spaces encountered in this paper (unless stated otherwise) are assumed to be Hausdorff. 


\section{Some USEFUl PRoperties}

In this section we recall some definitions and statements which will be used in the following sections.

Theorem 1 ([10]). Let $\mathcal{F}=\left\{f_{\alpha}\right\}_{\alpha \in S}$ be a family of functions $f_{\alpha}$ of a topological space $X_{\alpha}$ into a topological space $Y_{\alpha}$ respectively. The Cartesian product $\prod_{\alpha \in S} f_{\alpha}: \prod_{\alpha \in S} X_{\alpha} \rightarrow \prod_{\alpha \in S} Y_{\alpha}$ is a scatteredly continuous function if and only if the following conditions hold:

(i) all the functions $f_{\alpha}$ are scatteredly continuous;

(ii) all the functions $f_{\alpha}$, except maybe one, are weakly discontinuous;

(iii) all the functions $f_{\alpha}$, except maybe finite number, are continuous.

Recall that the Lindelof number $l(X)$ of a space $X$ is the smallest infinite cardinal $\kappa$ for which every open cover has a subcover of cardinality at most $\kappa$. The hereditary Lindelöf number $h l(X)$ of $X$ is the supremum of the cardinals $l(Y)$ ranging over subspaces $Y$ of $X$.

Also we need some other important result known as a theorem of Juhász. Firstly, recall that a space $X$ is called right separated (respectively left separated) if there is a well ordering $<$ of $X$ such that $\{y \in X: y<x\}$ is open (respectively closed) for any $x \in X$.

Theorem 2 ([16]). For any topological space $X$ we have

$$
h d(X)=\sup \{|Y|: Y \text { is a left separated subspace of } X\}
$$

and

$$
h l(X)=\sup \{|Y|: Y \text { is a right separated subspace of } X\} .
$$

Recall that a topological space $X$ is called scattered if each non-empty subspace $H$ of $X$ contains at least one point which is isolated in $H$.

Proposition 1. A space $X$ is right separated if and only if $X$ is scattered.

Lemma 1. Let $f: X \rightarrow Y$ be a scatteredly continuous function. Then for each non-empty subspace $A \subset X$ the set $C\left(\left.f\right|_{A}\right)$ is dense in $A$.

Proof. Without loss of generality we can assume that $A=X$. If $f: X \rightarrow Y$ is scatteredly continuous, then for each non-empty open set $U \subset X$ the restriction $\left.f\right|_{U}$ has a continuity point $x \in U$ which remains a continuity point of $f$. Therefore, $C(f)$ is dense in $X$.

Proposition 2. Let $f$ be an injective scatteredly continuous function from a topological space $X$ onto a scattered topological space $Y$. Then $X$ is also scattered.

Proof. Let us prove that the space $X$ contains an isolated point. Denote by $C(f)$ the set of continuity points of the function $f$. Since the space $f(C(f)) \subset Y$ is scattered, there is some $y_{0} \in f(C(f))$ which is an isolated point in $f(C(f))$. And since the restriction $\left.f\right|_{C(f)}: C(f) \rightarrow Y$ is continuous, the point $x_{0}=f^{-1}\left(y_{0}\right)$ is an isolated point in $C(f)$. Since $f: X \rightarrow Y$ is scatteredly continuous, due to Lemma 1 the set $C(f)$ is dense in $X$, and hence the point $x_{0}$ is an isolated point in $X$.

Similarly, one can prove that each non-empty subspace $A \subset X$ contains an isolated point. 


\section{The MAIN RESUlts}

From Theorem 1 it follows that the Cartesian product of two scatteredly continuous functions is not necessarily scatteredly continuous. It is also known that the hereditary Lindelöf number $h l$ is not saved by finite products. That is, the Cartesian product of two hereditary Lindelöf spaces is not necessarily a Lindelöf space. However, the following statement is true

Theorem 3. Let $f$ be a scatteredly continuous surjective function from a topological space $X$ onto a topological space $Y$. Then for each natural number $n$ we have $\mathrm{hl}\left(Y^{n}\right) \leqslant \operatorname{hl}\left(X^{n}\right)$.

Proof. Suppose that $f$ is a scatteredly continuous surjective function from a topological space $X$ onto a topological space $Y$. And let $\operatorname{id}_{X}: X \rightarrow X$ and $\operatorname{id}_{Y}: Y \rightarrow Y$ be the identity functions. We put $X^{n} \times X^{0}=X^{n}$ and $Y^{n} \times Y^{0}=Y^{n}$.

For each $i \in\{1, \ldots, n\}$ we consider the function

$$
\operatorname{id}_{X}^{n-i} \times f \times \operatorname{id}_{Y}^{i-1}: X^{n-i} \times X \times Y^{i-1} \rightarrow X^{n-i} \times Y^{i} .
$$

Since the functions $\operatorname{id}_{X}$ and $\operatorname{id}_{Y}$ are continuous and the function $f$ is scatteredly continuous, due to Theorem 1 the function $\operatorname{id}_{X}^{n-i} \times f \times \mathrm{id}_{Y}^{i-1}$ is scatteredly continuous.

Let us prove that $\mathrm{hl}\left(X^{n-i} \times Y^{i}\right) \leqslant \mathrm{hl}\left(X^{n-i+1} \times Y^{i-1}\right)$ for each $i \in\{1, \ldots, n\}$. Suppose that there is $k \in\{1, \ldots, n\}$ such that $\mathrm{hl}\left(X^{n-k} \times Y^{k}\right)>\operatorname{hl}\left(X^{n-k+1} \times Y^{k-1}\right)$. Applying Theorem 2 and Proposition 1 find a scattered subspace $Z \subset X^{n-k} \times Y^{k}$ such that $|Z|=h l\left(X^{n-k} \times Y^{k}\right)$. For an arbitrary $z \in Z$ let us fix some point $x_{z} \in\left(\operatorname{id}_{X}^{n-k} \times\right.$ $\left.f \times \operatorname{id}_{Y}^{k-1}\right)^{-1}(z)$. Put $A=\left\{x_{z}: z \in Z\right\}$. The restriction $\operatorname{map}_{X} \operatorname{id}_{X}^{n-k} \times f \times\left.\operatorname{id}_{Y}^{k-1}\right|_{A}: A \rightarrow Z$ is bijective and scatteredly continuous. Using Proposition 2 we get that subspace $A$ is scattered and $|A|=|Z|=h l\left(X^{n-k} \times Y^{k}\right)>h l\left(X^{n-k+1} \times Y^{k-1}\right)$ which is a contradiction to Theorem 2. Therefore $\operatorname{hl}\left(X^{n-i} \times Y^{i}\right) \leqslant \operatorname{hl}\left(X^{n-i+1} \times Y^{i-1}\right)$ for each $i \in\{1, \ldots, n\}$.

Consequently,

$$
\operatorname{hl}\left(Y^{n}\right) \leqslant \operatorname{hl}\left(X \times Y^{n-1}\right) \leqslant \operatorname{hl}\left(X^{2} \times Y^{n-2}\right) \leqslant \ldots \leqslant \operatorname{hl}\left(X^{n}\right) .
$$

Recall that spaces $X$ and $Y$ are scatteredly homeomorphic if there is a bijective map $f: X \rightarrow Y$ such that both $f$ and $f^{-1}$ are scatteredly continuous.

Proposition 3. Each topological space is scatteredly homeomorphic to a left separated space.

Proof. Let $(X, \tau)$ be a topological space with the topology $\tau$. Fix some well ordering $<$ of the set $X$. Choose the family $\tau \cup\{\{a \leqslant x: x \in X\}: a \in X\}$ to be a subbase of a new topology $\tau^{\prime}$ on $X$. Obviously, the space $\left(X, \tau^{\prime}\right)$ is left separated. Consider the identity function $i:(X, \tau) \rightarrow\left(X, \tau^{\prime}\right)$. Note that for an arbitrary non-empty subset $A$ of $X$, the smallest element of the set $A$ in the well ordering < is a point of continuity of the restriction $\left.i\right|_{A}$. Hence the identity function $i$ is scatteredly continuous. Obviously, the function $i^{-1}:\left(X, \tau^{\prime}\right) \rightarrow(X, \tau)$ is continuous.

Example 1. Consider the real line $\mathbb{R}$ equipped with the standard topology. Proposition 3 implies that there is a bijective scatteredly continuous function from $\mathbb{R}$ onto some left separated space $Y$. The real line $\mathbb{R}$ equipped with the standard topology is a separable 
metrizable space. However, since space $Y$ is left separated, according to Theorem 2 we have the following

$$
h d(Y)=|Y|=|\mathbb{R}|>\aleph_{0} .
$$

Theorem 4. Let $f: X \rightarrow Y$ be a barely continuous surjective function between topological spaces. Then $l(Y) \leqslant h l(X)$.

Proof. Let $f: X \rightarrow Y$ be a barely continuous surjective function and $\operatorname{hl}(X) \leqslant \tau$. Suppose that $l(Y)>\tau$. Without loss of generality, we can assume that the function $f$ is bijective. Since $l(Y)>\tau$, there is a $\tau$-centered family $\mathcal{F}$ of closed subsets of $Y$ such that $\bigcap \mathcal{F}=\bigcap\{F: F \in \mathcal{F}\}=\varnothing$. We can assume that the family $\mathcal{F}$ contains the intersections of its $\tau$-element subfamilies. Let $A=\bigcap\left\{\operatorname{cl}_{X}\left(f^{-1}(F)\right): F \in \mathcal{F}\right\}$. Since the family $\left\{\operatorname{cl}_{X}\left(f^{-1}(F)\right): F \in \mathcal{F}\right\}$ is $\tau$-centered and $\operatorname{hl}(X) \leqslant \tau$, the set $A$ is not empty. The $\tau$ centeredness means that $\bigcap \mathcal{E} \neq \varnothing$ for any subfamily $\mathcal{E} \subset \mathcal{F}$ having cardinality $|\mathcal{E}| \leq \tau$. Let us show that there is a set $F_{0} \in \mathcal{F}$ such that $f^{-1}\left(F_{0}\right) \subset A$. Assume that for all $F \in \mathcal{F}$ we have $f^{-1}(F) \backslash A \neq \varnothing$. Then $\left\{\mathrm{cl}_{X \backslash A}\left(f^{-1}(F) \backslash A\right): F \in \mathcal{F}\right\}$ is a $\tau$-centered family of sets closed in $X \backslash A$ and

$$
\begin{aligned}
\bigcap\left\{\operatorname{cl}_{X \backslash A}\left(f^{-1}(F) \backslash A\right): F \in \mathcal{F}\right\} & \subset \bigcap\left\{\operatorname{cl}_{X}\left(f^{-1}(F)\right): F \in \mathcal{F}\right\} \cap X \backslash A= \\
& =A \cap X \backslash A=\varnothing .
\end{aligned}
$$

This contradicts with the fact that $l(X \backslash A) \leqslant \tau$. Since $f$ is barely continuous and $A$ is a non empty closed subset of $X$, there is a continuity point $x \in A$ of the restriction $\left.f\right|_{A}: A \rightarrow Y$. Since $\bigcap \mathcal{F}=\varnothing$, there is $F^{*} \in \mathcal{F}$ such that $f\left(x^{*}\right) \notin F^{*}$. Let $F^{* *}=F^{*} \cap F_{0}$. Since $x^{*} \in A$, we have that $x^{*} \in \mathrm{cl}_{X}\left(f^{-1}\left(F^{* *}\right)\right)$. And from the continuity of the restriction $\left.f\right|_{A}$ at the point $x^{*}$ we have $f\left(x^{*}\right) \in \operatorname{cl}_{Y}\left(f\left(f^{-1}\left(F^{* *}\right)\right)\right)=F^{* *}$. The resulting contradiction proves that $l(Y) \leqslant \tau$.

The following example shows that the fact that $Y$ is a barely continuous image of the space $X$ does not imply that $h l(Y) \leqslant h l(X)$.

Example 2. Let space $X$ be the closed interval $[0,1]$ with the usual topology and let $M$ be a Bernstein subset of $X$, that is, a subspace of space $X$ of cardinality continuum that contains no uncountable compact subsets.

It is easy to check that the family of all sets of the form $U \cup K$, where $U$ is an open set in $X$ and $K \subset M$, forms a topology base on the set $X$. We denote by $Y$ the set $X$ with this topology. Let us show that the identity function id: $X \rightarrow Y$ is barely continuous.

Let $F$ be a closed subset of $X$. If $F \cap(X \backslash M) \neq \varnothing$, then each point of $F \cap(X \backslash M)$ is a continuity point of the restriction $i d_{F}: F \rightarrow Y$. If $F \cap(X \backslash M)=\varnothing$, then $F \subset M$. Since $F$ is a closed subset of the segment $[0,1]$ with the usual topology, $F$ is compact. Since $F$ is a subset of the space $M, F$ is countable, and hence has isolated points. These points will be continuity points of the restriction $\operatorname{id}_{F}: F \rightarrow Y$. Consequently, the function id is barely continuous. Since $X$ has a countable base, $h l(X) \leqslant \aleph_{0}$. By the construction, $|M|=2^{\aleph_{0}}$ and $M$ is a discrete subspace of the space $Y$. Then $h l(Y)=2^{\aleph_{0}}>\aleph_{0}$.

Corollary 1. For the metrizable spaces, separability is invariant with respect to the barely continuous functions. 
Proof. Let $X$ be a metrizable separable space. Then $\operatorname{hl}(X) \leqslant \aleph_{0}$. According to the Theorem $4 l(Y) \leqslant \aleph_{0}$. And since $Y$ is metrizable, it is also separable.

Corollary 2. The Cartesian product of two barely continuous maps need not be a barely continuous map.

Proof. Consider the space $X=[0 ; 1)$. Let $\tau_{S}$ be the Sorgenfrey topology on $X$ and $\tau$ be the usual topology on $X$, respectively. Consider also the identity function $i:(X, \tau) \rightarrow$ $\left(X, \tau_{S}\right)$. The function $i$ is barely continuous. However since the product $(X, \tau) \times(X, \tau)$ is metrizable separable and $l\left(\left(X, \tau_{S}\right) \times\left(X, \tau_{S}\right)\right)>\aleph_{0}$, the Cartesian product $i \times i$ is not barely continuous.

\section{REFERENCES}

1. А. В. Архангельский, Строение и классификация топологических пространств и кардиналъные инварианты, УМН 33 (1978) nо. 6(204), 29-84; English version: A. V. Arkhangelskii, Structure and classification of topological spaces and cardinal invariants, Russian Math. Surveys, 33 (1978), no. 6, 33-96. DOI: 10.1070/RM1978v033n06ABEH003884

2. А. В. Архангельский, Б. М. Бокало, Касание топологий и тангенииалънъе свойства топологических пространств, Тр. ММО, 54 (1992), 160-185; English version: A. V. Arkhangelskii and B. M. Bokalo, Tangency of topologies and tangential properties of topological spaces, Trans. Mosc. Math. Soc. 1993 (1993), 139-163.

3. R. Baire, Sur les fonctions de variables reelles, Annali di Mat. (3) 3 (1899), no. 1, 1-123. DOI: $10.1007 /$ BF02419243

4. T. Banakh and B. Bokalo, On scatteredly continuous maps between topological spaces, Topology Appl. 157 (2010), no. 1, 108-122. DOI: 10.1016/j.topol.2009.04.043

5. T. Banakh, B. Bokalo, and N. Kolos, On $\sigma$-convex subsets in spaces of scatteredly continuous functions, Math. Bulletin Shevchenko Sci. Soc. 9 (2012), 401-413.

6. T. Banakh, B. Bokalo, and N. Kolos, On $\infty$-convex sets in spaces of scatteredly continuous functions, Topology Appl. 169 (2014), 33-44. DOI: 10.1016/j.topol.2014.02.030

7. T. Banakh, B. Bokalo, and N. Kolos, Topological properties preserved by weakly discontinuous maps and weak homeomorphisms, Topology Appl. 221 (2017), 91-106.

DOI: $10.1016 /$ j.topol.2017.02.036

8. Т. О. Банах, С. М. Куцак, В. К. Маслюченко, О. В. Маслюченко, Прямі та обернені задачі берівсъкої класифікачї інтегралів, залежних від параметра, Укр. мат. журн. 56 (2004), no. 11, 1443-1457; English version: T. O. Banakh, S. M. Kutsak, V. K. Maslyuchenko, and O. V. Maslyuchenko, Direct and inverse problems of Baire classifications of integrals dependent on a parameter, Ukr. Math. J. 56 (2004), no. 11, 1721-1737.

DOI: $10.1007 / \mathrm{s} 11253-005-0147-1$

9. B. Bokalo and N. Kolos, When does $S C_{p}(X)=\mathbb{R}^{X}$ hold?, Topology 48 (2009), no. 2-4 178-181. DOI: $10.1016 /$ j.top.2009.11.016

10. B. M. Bokalo and N. M. Kolos, On operations on some classes of discontinuous functions, Carpathian Math. Publ. 3 (2011), no. 2, 36-48.

11. B. Bokalo and N. Kolos, On normality of spaces of scattredly continuous maps, Mat. Stud. 35 (2011), no. 2, 196-204.

12. B. Bokalo and O. Malanyuk, On almost continuous mappings, Mat. Stud. 9 (1995), no. 1, 90-93 (Ukrainian).

13. F. Chaatit and H. Rosenthal, On differences of semi-continuous functions, Quaest. Math. 23 (2000), no. 3, 295-311. DOI: 10.2989/16073600009485979 
14. R. Engelking, General topology. Warszawa, PWN, 1977.

15. R. Haydon, E. Odell, and H. Rosenthal, On certain classes of Baire-1 functions with applications to Banach space theory, Functional Analysis, Austin, TX, 1987/1989, Lecture Notes in Math., vol. 1470, Springer, Berlin, 1991, pp. 1-35. DOI: 10.1007/BFb0090209

16. I. Juhász, Cardinal function in topology - ten years later, Math. Centre Tracts 123, Amsterdam, 1981.

17. O. O. Karlova and O. V. Sobchuk, On $H_{1}$-compositors and piecewise continuous mappings, Mat. Stud. 38 (2012), no. 2, 139-146.

18. E. Michael and I. Namioka, Barely continuous functions, Bull. Acad. Sci. Ser. Sci. Math. Astronom. Phys. 24 (1976), 889-892.

19. V. A. Vinokurov, Strong regularizability of discontinuous functions, Dokl. Akad. Nauk SSSR 281 (1985), no. 2, 265-269 (Russian).

Стаття: надійшла до редколегї̈ 28.08.2018

доопрацвована 12.09.2018

прийнята до друку 26.12.2018

\title{
ІНВАРІАНТНІСТЬ ЧИСЛА ЛІНДЕЛЬОФА ЗА ДЕЯКИХ РОЗРИВНИХ ВІДОБРАЖЕНЬ
}

\author{
Богдан БОКАЛО, Надія КОЛОС \\ Лъвівсъкий націоналъний університет імені Івана Франка, \\ вул. Університетсъка 1, 79000, Лъвів \\ e-mail:b.m.bokalo@gmail.com,nadiya_kolos@ukr.net
}

Відображення $f: X \rightarrow Y$ між топологічними просторами називають розріджено неперервним (насичено неперервним), якщо для кожного непорожнього (замкненого) підпростору $A \subset X$ звуження $\left.f\right|_{A}$ має точку неперервності. Доведено таке: якщо відображення $f: X \rightarrow Y$ є сюр'єктивним розріджено неперервним (насичено неперервним), то для довільного натурального числа $n$ маємо $\mathrm{hl}\left(Y^{n}\right) \leqslant \mathrm{hl}\left(X^{n}\right)(l(Y) \leqslant h l(X)$, відповідно).

Ключові слова: розріджено неперервне відображення, слабко розривне відображення, насичено неперервне відображення, число Ліндельофа. 